\section{Diabetologist (Diabetes} Specialist)

\section{Janine Sanchez}

Department of Pediatrics, University of Miami, Miami, FL, USA

\section{Synonyms}

Endocrinologist

\section{Definition}

A diabetologist is a physician with expertise in diabetes care. The physician is often board certified in pediatric or adult endocrinology with special interest or extra training in diabetes care or research. However, diabetology is not a recognized medical specialty and has no formal training programs. Thus, any physician whose practice and/or research efforts are concentrated mainly in diabetes care may be considered a diabetologist/diabetes specialist.

\section{Cross-References}

D Diabetes

- Endocrinology

\section{References and Further Reading}

Menon, R. (2003). Pediatric diabetes (1st ed.). Norwell: Springer.

Sperling, M. A. (2009). Pediatric endocrinology (3rd ed.). Philadelphia: W.B. Saunders. 